\title{
Ventral root re-implantation is better than peripheral nerve transplantation for motoneuron survival and regeneration after spinal root avulsion injury
}

Huanxing Su" ${ }^{*}$, Qiuju Yuan², Dajiang Qin² ${ }^{2}$ Xiaoying Yang ${ }^{2}$, Wai-Man Wong ${ }^{2}$, Kwok-Fai So ${ }^{2,4}$ and Wutian Wu 2,3,4* $^{*}$

\begin{abstract}
Background: Peripheral nerve (PN) transplantation and ventral root implantation are the two common types of recovery operations to restore the connection between motoneurons and their target muscles after brachial plexus injury. Despite experience accumulated over the past decade, fundamental knowledge is still lacking concerning the efficacy of the two microsurgical interventions.

Methods: Thirty-eight adult female Sprague-Dawley rats were divided into 5 groups. Immediately following root avulsion, animals in the first group $(n=8)$ and the second group $(n=8)$ received PN graft and ventral root implantation respectively. The third group $(n=8)$ and the fourth group $(n=8)$ received PN graft and ventral root implantation respectively at one week after root avulsion. The fifth group received root avulsion only as control $(n=6)$. The survival and axonal regeneration of severed motoneurons were investigated at 6 weeks post-implantation.
\end{abstract}

Results: Re-implantation of ventral roots, both immediately after root avulsion and in delay, significantly increased the survival and regeneration of motoneurons in the avulsed segment of the spinal cord as compared with PN graft transplantation.

Conclusions: The ventral root re-implantation is a better surgical repairing procedure than PN graft transplantation for brachial plexus injury because of its easier manipulation for re-implanting avulsed ventral roots to the preferred site, less possibility of causing additional damage and better effects on motoneuron survival and axonal regeneration.

Keywords: Avulsion, Peripheral nerve graft transplantation, Ventral root re-implantation, Motoneuron survival and regeneration

\section{Background}

PN grafts have been frequently used to restore the connectivity of peripheral targets with the spinal cord after avulsion injury to the brachial plexus [1,2]. The scar tissue containing astrocytic processes and numerous collagen fibers and the formation of the neuroma of avulsed spinal roots at the CNS-PNS border make it impossible

\footnotetext{
* Correspondence: Huanxingsu@umac.mo; wtwu@hkucc.hku.hk

'State Key Laboratory of Quality Research in Chinese Medicine, Institute of Chinese Medical Sciences, University of Macau, Macao, China

${ }^{2}$ Department of Anatomy, Li Ka Shing Faculty of Medicine, The University of Hong Kong, 21 Sassoon Road, Pokfulam, Hong Kong SAR, China Full list of author information is available at the end of the article
}

to re-attach them directly to the spinal cord $[3,4]$. Thus, a PN graft is often applied to bridge the gap between the spinal nerve and the spinal cord. Experimental settings using PN transplantation have demonstrated its capacity of inducing reinnervation and protecting avulsed motoneurons from degeneration in various animal models [5-11]. Clinical application of PN grafts by direct implantation into the spinal cord leads to reinnervation and functional recovery in the proximal muscles in patients with severe brachial plexus injury [12]. In most cases, PN grafts were implanted into the lateral white matter of the spinal cord via the dorsal approach, 
resulting in the change of axon outgrowth direction from ventrally to laterally. Although the insertion site had been optimized so as to minimize functional disorder of the spinal cord [13], implantation may inflict damage to a notyet traumatized area of the spinal cord. These limitations may discourage the clinical application of PN transplantation in surgically treating brachial plexus injury.

Surgical replantation of avulsed ventral roots was demonstrated to be effective in rescuing motoneurons, inducing axonal regeneration into the re-implanted ventral roots, and even promoting functional reinnervation of peripheral targets in various animal models [14-19]. Nearly all these implantation studies inserted the avulsed ventral rootlets into the parenchyma of the spinal cord to stimulate regeneration, which may cause additional damage to the spinal cord and require more challenging surgical skills.

We have developed a new microsurgical technique to restore the connection by positioning the avulsed ventral root on the ventrolateral pial surface of the spinal cord instead of inserting the ventral rootlets into the parenchyma of the spinal cord [20,21]. Re-implantation of the avulsed ventral root by attachment to the pial surface of rat spinal cords, both immediately after root avulsion and in delay, has been shown to be capable of inducing axonal regeneration of severed motoneurons to reinnervate muscle targets, leading to recovery of hand functions [21,22]. These findings suggest that implantation of the ventral root directly into the parenchyma of the spinal cord is not essential. Re-implantation of the avulsed ventral roots on the ventrolateral pial surface of the spinal cord could be less technically demanding and more easily manipulated through the dorsal approach. It could be a useful model to study axonal regeneration from CNS to PNS, identify inhibitory molecules in the pathway along axonal extension, and study the target innervation after brachial plexus injury.

Despite experience accumulated over the past decade, fundamental knowledge is still lacking concerning the efficacy of these microsurgical interventions. In the present study we investigated the survival and axon regeneration of severed motoneurons in the two distinct implantation models through the dorsal approach, i.e. PN graft transplantation model and ventral root implantation model. The results of the study provide evidence that the superficial implantation of ventral roots has better effects on motoneuron survival and regeneration after spinal root avulsion and may have clinical application potential in treating brachial plexus injury.

\section{Methods}

Thirty-eight adult female Sprague-Dawley rats (220$250 \mathrm{~g}$ ) were used in the present study and divided into 5 groups. Animals in the first group and the second group received $\mathrm{PN}$ graft transplantation $(\mathrm{n}=8)$ and ventral root implantation $(n=8)$ respectively immediately following root avulsion; animals in the third group and fourth group received PN graft transplantation $(n=8)$ and ventral root re-implantation $(n=8)$ respectively at 1 week after root avulsion. The fifth group received root avulsion only as control $(n=6)$. All surgical interventions and subsequent care and treatment were approved by the Committee on the Use of Live Animals for Teaching and Research of the University of Hong Kong. Animals were anesthetized with an intraperitoneal injection of ketamine $(80 \mathrm{mg} / \mathrm{kg})$ and xylazine $(8 \mathrm{mg} / \mathrm{kg})$. Root avulsion was performed as described in our previous publications [20,21]. Briefly, a dorsal hemi-laminectomy on the right side of the sixth cervical vertebra was carried out under aseptic conditions. The 7th cervical spinal roots (C7) were avulsed by traction with a fine hook under a surgical microscope. For PN graft transplantation, an autologous saphenous nerve about $20 \mathrm{~mm}$ in length was harvested and a myelotomy approximately

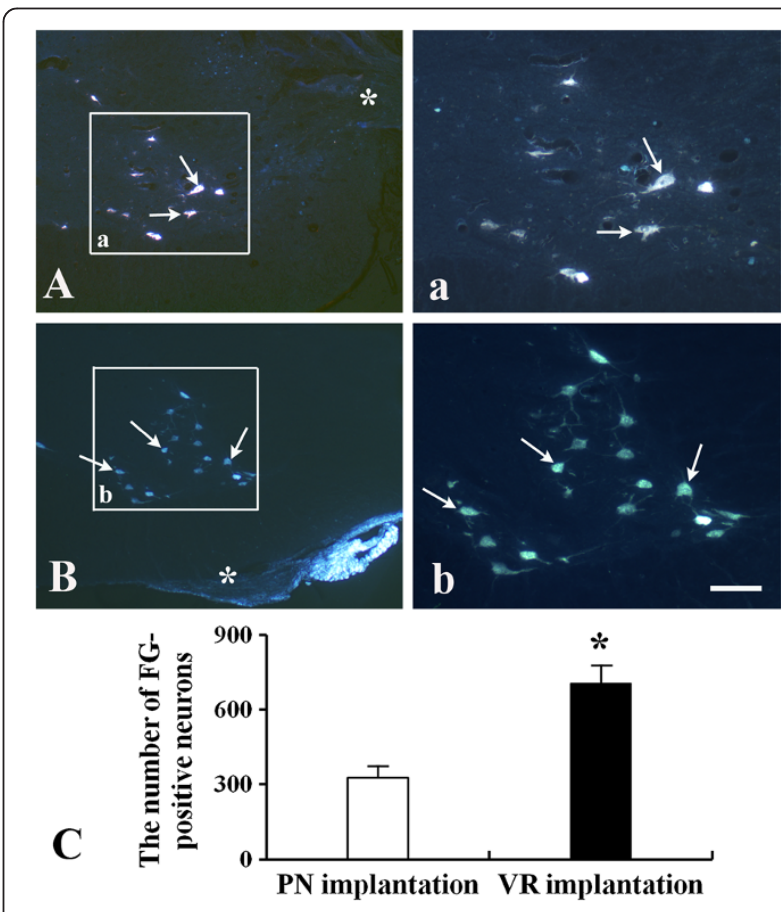

Figure 1 Effects of PN graft transplantation and ventral root (VR) re-implantation on the axonal regeneration of avulsed motoneurons as revealed by retrograde FG-labeling at 6 weeks post-implantation. (A) A representative micrograph of spinal cross sections showing FG-positive neurons (arrows) present in the ventral horn of the animals with PN graft transplantation (asterisk). (B) A representative micrograph of spinal cross sections showing FG-positive neurons (arrows) in the ventral horn of the animals with VR re-implantation (asterisk). (a and $\mathbf{b}$ ) Micrographs made under higher magnification of the areas of interest in $A$ and $B$, respectively. (C) The number of regenerating motoneurons in the VR re-implanted animals was significantly higher than that in the PN transplanted animals ( ${ }^{*} p<0.001$; scale bar: $200 \mu \mathrm{m}$ in $\mathbf{A}$ and $\mathbf{B} ; 80 \mu \mathrm{m}$ in $\mathbf{a}$ and $\mathbf{b}$ ). 
$1 \mathrm{~mm}$ deep was performed at the lateral funiculus of the C7 spinal cord. The PN was implanted into the myelotomy groove and further secured in position by suturing the epineurium of proximal end with 11-0 suture on the pia mater. The distal end of the graft was implanted into a juxtaposed skeletal muscle. For ventral root re-implantation, the avulsed ventral root was repositioned on the ventrolateral pial surface of the spinal cord via the dorsal approach. The avulsed dorsal root was anchored to the edge of the dura mater with a suture to fix the repositioned ventral root in place. All the animals were allowed to survive for 6 weeks after PN grafting or ventral root implantation. Three days before the end of the survival period, $0.5 \mu \mathrm{l}$ of $3 \%$ FG was injected into the $\mathrm{C} 7$ spinal nerve or the PN graft at the point $10 \mathrm{~mm}$ from the spinal cord to label the regenerating neurons.

At the end of the survival period, the animals were killed with a lethal dose of sodium pentobarbital and perfused intracardially with $0.01 \mathrm{M}$ PBS, followed by perfusion with $200-300 \mathrm{ml}$ of fixative solution contai- ning $4 \%$ paraformaldehyde in $0.1 \mathrm{M}$ PB. Spinal cords were harvested and postfixed in fresh fixative solution overnight and subsequently placed in 30\% sucrose- 0 . $1 \mathrm{M} \mathrm{PB}$ at $4^{\circ} \mathrm{C}$ for $2-3$ days. The $\mathrm{C} 7$ segment of the spinal cord was cut into $30 \mu \mathrm{m}$ cross sections on a microtome (American Optical Company, NY, USA), mounted on the slides, protected by cover slips and examined under a fluorescence microscope to count FG-positive cells. Only labeled neurons with visible nuclei were counted. Then we quantified the surviving motoneurons on neutral red stained sections (one of every other cross section) according to a previously described method [23,24]. Only those nucleolated profiles apparently belonging to motoneurons were counted to avoid duplication. The number of motoneurons on the intact side would be expressed as $100 \%$ of the control value. The number of surviving motoneurons on the lesioned side was described quantitatively as percentages of the normal control number.

Statistical differences between two groups were determined by two-tailed Student's $t$ test. Multiple group
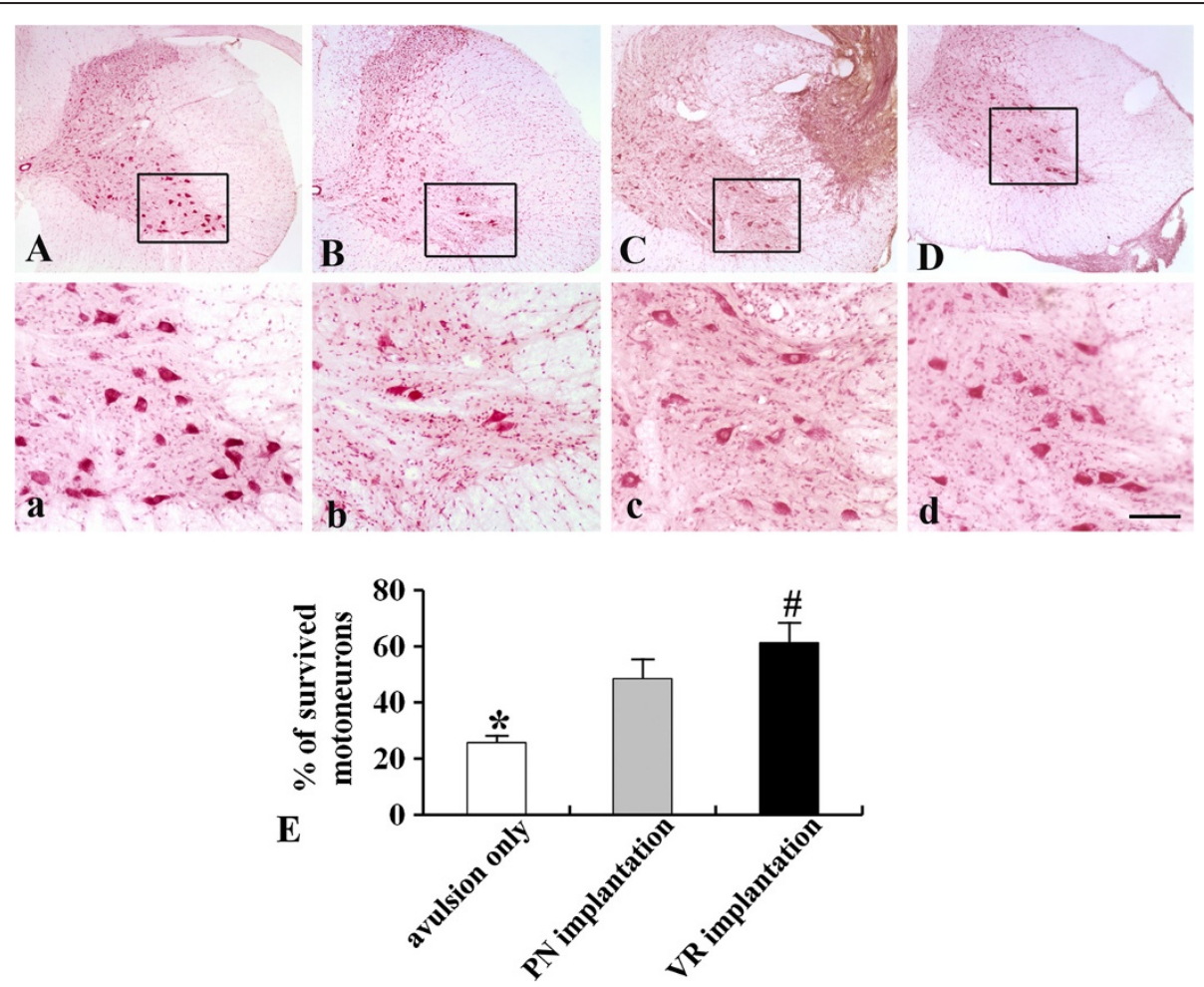

Figure 2 Effects of PN graft transplantation and VR re-implantation on the survival of host motoneurons as revealed by neutral red staining at 6 weeks after root avulsion. (A) Normal animals. (B) Animals receiving root avulsion only. (C) Animals receiving PN graft transplantation. (D) Animals receiving VR re-implantation. (a, b, $\mathbf{C}$, and $\mathbf{d})$ Micrographs made under higher magnification of the areas of interest in $\mathbf{A}, \mathbf{B}, \mathbf{C}$, and $\mathbf{D}$, respectively. (E) PN graft transplantation or VR re-implantation significantly increased the survival rate of motoneurons compared to controls. Furthermore, the survival rate of motoneurons in the animals receiving VR re-implantation was significantly higher than that seen in the animals receiving PN graft transplantation (*: $p<0.001$ compared to PN or VR implantation; \#: $p<0.05$ compared to PN implantation; scale bar: $300 \mu \mathrm{m}$ in $\mathbf{A}, \mathbf{B}, \mathbf{C}$ and $\mathbf{D} ; 100 \mu \mathrm{m}$ in $\mathbf{a}, \mathbf{b}, \mathbf{c}$ and $\mathbf{d})$. 
comparisons were made by one-way ANOVA and Tukey post hoc test. Data were presented as mean \pm SEM. The significance level was set to 0.05 for all comparisons.

\section{Results}

Success of PN graft transplantation and ventral root implantation was confirmed by examining the integration of nerve with the host spinal cord during harvesting. All replanted PN grafts or ventral roots were found to be firmly connected with the spinal cord. Cross sections of the $\mathrm{C} 7$ segment further showed that the implanted PN (Figure 1A) and ventral root (Figure 1B) were nicely connected to the spinal cord. At 6 weeks post-implantation, retrograde labeling with FG revealed that approximately $325 \pm 48.7$ neurons in C7 spinal segment regenerated axons into the PN graft which was implanted immediately after root avulsion (Figure 1A and 1C). Notably, the number of regenerating neurons was markedly increased in the animals with ventral root implantation and about $703 \pm 76.5$ FG-positive neurons were detected in the ventral horn of these animals $(\mathrm{P}<0.001$ compared to $\mathrm{PN}$-implanted animals, Figure $1 \mathrm{~B}$ and $1 \mathrm{C})$.

We then investigated the survival rate of motoneurons in these two implantation models. In the control group (root avulsion only), only $25.6 \pm 2.8 \%$ of motoneurons survived in the ventral horn of the lesioned side 6 week after injury (Figure $2 \mathrm{~B}$ and $2 \mathrm{E}$ ) compared with the normal side (Figure 2A). Transplantation of a PN graft significantly increased the number of surviving motoneurons $(48.3 \pm 7.2 \%)$ compared with the control $(\mathrm{P}<0.001$; Figure $2 \mathrm{C}$ and $2 \mathrm{E}$ ). The number of surviving motoneurons was further enhanced in the animals receiving ventral root implantation and $61.2 \pm 7.3 \%$ of motoneurons survived at 6 weeks after injury, which is significantly higher than that in the animals receiving $\mathrm{PN}$ graft transplantation $(\mathrm{P}<0.05$, Figure 2D and 2E).

A short time lag between the injury and the implantation surgery is recognized as a significant factor for root avulsion repair. Using the delayed implantation method, we further compared the effects of these two implantation models on the regeneration and survival of motoneurons. The PN graft or the avulsed ventral root was implanted at 1 week after root avulsion. At 6 weeks after implantation, the animals were killed. FG-labeling showed that delayed implantation of the PN graft induced $287 \pm 32.3$ neurons to regenerate their axons into the graft (Figure 3A1). The number of regenerating neurons was increased in the animals with delayed implantation of the ventral root and about $584 \pm 42.5$ FG-positive neurons were detected in the ventral horn of these animals $(\mathrm{P}<0.001$ compared to delayed $\mathrm{PN}$ implanted animals, Figure 3B1 and 3C). Similarly, more surviving motoneurons were found in the ventral horn of the animals receiving delayed ventral root

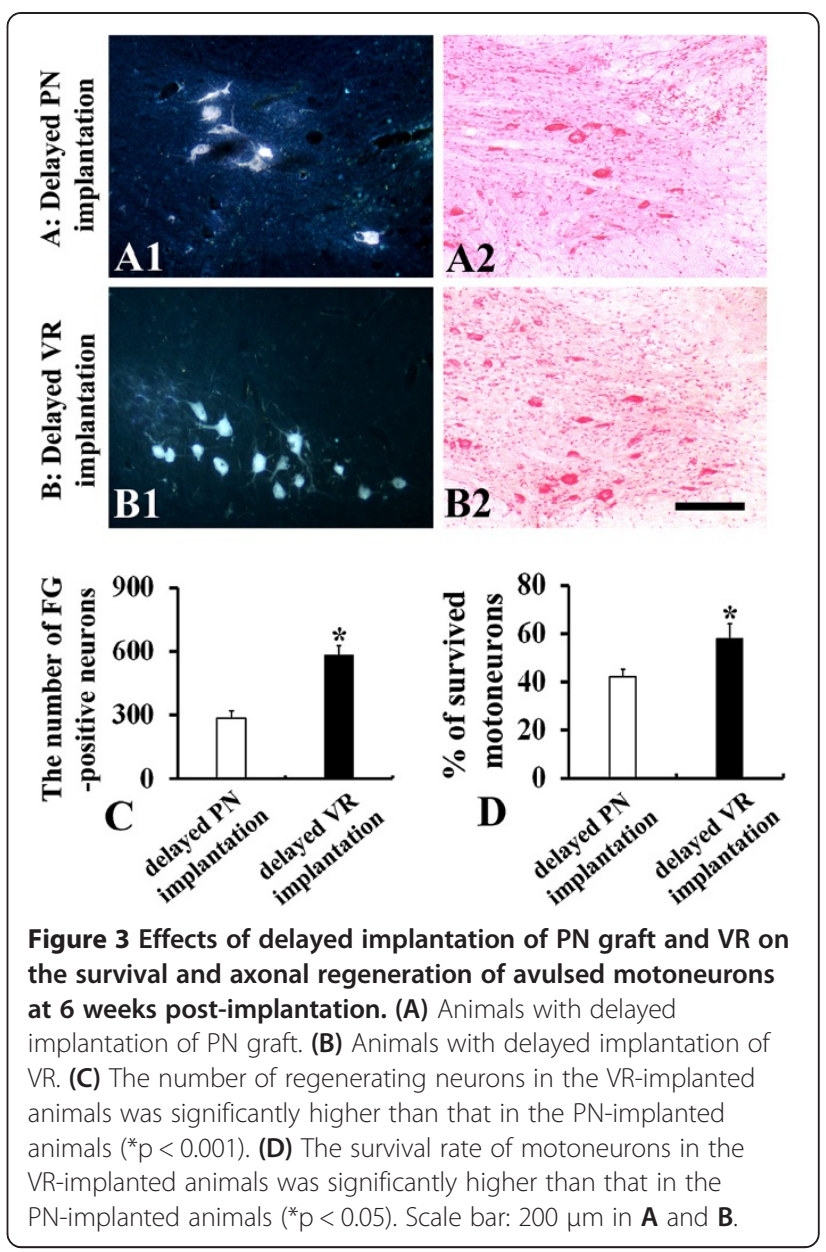

implantation and $57.9 \pm 6.1 \%$ of motoneurons survived at 6 weeks after implantation, which is significantly higher than $42.7 \pm 3.2 \%$ in the animals receiving delayed $\mathrm{PN}$ implantation $(\mathrm{P}<0.05$, Figure $3 \mathrm{~A} 2, \mathrm{~B} 2$ and $3 \mathrm{D})$.

\section{Discussion}

Ventral root re-implantation and PN graft transplantation are the two types of microsurgical interventions commonly used to restore the connection between motoneurons and their target muscles for the treatment of root avulsion injury. They can be performed via either a dorsal $[5-8,14,25,26]$ or a ventral approach $[10,27,28]$. The dorsal approach is easier to perform in which only retraction of paraspinal muscles and hemi-laminectomy are needed to access the dura and the cord. The ventral approach has been used in several studies in order to implant avulsed rootlets into the original ventral exit zone $[10,13,27,29,30]$. However, it should be noted that it is more technically demanding for the implantation surgery via the ventral approach in which partial corporectomy is needed to expose the dura and avulsed area of the cord. In the present study we re-implanted the avulsed ventral roots on the ventrolateral pial surface of 
the spinal cord through the dorsal approach. Anatomical evaluations during harvesting spinal cords show that superficially replanted rootlets were firmly attached to the ventrolateral side of the cord, demonstrating that avulsed ventral rootlets can be repositioned to the preferred site (the ventral root outlet area) via the dorsal approach in the superficial implantation strategy.

After transplantation of PN grafts or implantation of avulsed ventral roots, significant numbers of motoneurons survived. Implanted PN grafts and ventral roots exert neuroprotective roles possibly through releasing neurotrophic substances that act on the perikarya of severed motoneurons and/or activate specific survival genes. The ventral exit zone possesses natural conduits connecting with motoneurons [31]. Repositioned ventral roots which are attached to the ventrolateral surface of the spinal cord may diffuse neurotrophic factors more efficiently than laterally implanted PN grafts, which do not connect with those natural conduits. Moreover, an interesting study reported that the ventral root preferentially supported motor axon regeneration since mRNA for pleiotrophin (PTN) and glial cell line-derived neurotrophic factor was upregulated to a greater degree in the ventral root [32]. These may account for the stronger effect of superficially implanted ventral roots on promoting motoneuron survival and regeneration compared to PN grafts. In addition, the distal-target environment between the two groups is different in the present study: the distal end of the PN graft was inserted in a juxtaposed muscle, while the distal part of avulsed ventral root was connected to the nerve. Whether the difference in the distal-target environment between the two groups affects motoneuron survival and regeneration needs to be further investigated in future studies.

Motoneurons in the ventral horn possess dendrites reaching the subpial surface as evidenced by intracellular injection experiments [33]. Following root avulsion, motoneurons respond with a changing polarity towards production of axons, sometimes even from the dendritic tree [34]. In addition, avulsion usually leaves tufts of the most proximal parts of roots attached to the spinal cord surface. All these may help injured motoneurons regrow their axons into the implanted ventral roots on the surface of the spinal cord.

Root avulsion most frequently occurs in multitraumatized events and it is usually difficult to determine the exact location and degree of the injury. Therefore, delayed nerve repair has been advocated. However, avulsed spinal nerve roots have retracted in the delayed treatment, which reduces the length of root available for reconnection to the cord. PN transplantation has been utilized experimentally and clinically to bridge the gap resulting from spinal nerve retraction $[9,12]$. However, PN transplantation may cause additional damage to the spinal cord due to the insertion procedure. Harvesting the PN graft from patients also causes additional injury in another part of the body. The superficial implantation of avulsed ventral root in our study obviates these limitations associated with PN transplantation. Moreover, in the present study, we have demonstrated that avulsed ventral roots can be reconnected to the spinal cord after one week delay, and the repair can rescue more motoneurons and permit more surviving neurons to regenerate axons into the superficially implanted ventral root compared to the PN graft. The success of delayed implantation of avulsed ventral roots, though in only one week delay, raises the possibility of an alternative treatment for patients with avulsion injuries of the ventral roots.

\section{Conclusions}

The ventral root re-implantation is a better surgical repairing procedure than $\mathrm{PN}$ graft transplantation for brachial plexus injury because of its easier manipulation for reimplanting avulsed ventral roots to the preferred site, less possibility of causing additional damage and better effects on motoneuron survival and axonal regeneration.

\section{Competing interests}

The authors declare that they have no competing interests.

\section{Authors' contributions}

Conceived and designed the experiments: HS, KS, WW; Performed the experiments: QY, DQ, XY, WW; Analyzed the data: HS, KS, WW; Wrote the paper: HS, WW. All authors read and approved the final manuscript.

\section{Acknowledgments}

This study was supported by Hong Kong SCI Fund and multi-year research grant, university of Macau, MYRG122 (Y1-L3)-ICMS12-SHX.

\section{Author details}

'State Key Laboratory of Quality Research in Chinese Medicine, Institute of Chinese Medical Sciences, University of Macau, Macao, China. ${ }^{2}$ Department of Anatomy, Li Ka Shing Faculty of Medicine, The University of Hong Kong, 21 Sassoon Road, Pokfulam, Hong Kong SAR, China. ${ }^{3}$ Research Center of Reproduction, Development and Growth, Li Ka Shing Faculty of Medicine, The University of Hong Kong, Pokfulam, Hong Kong SAR, China. ${ }^{4} \mathrm{GHM}$ Institute of CNS Regeneration, Jinan University, Guangzhou, China.

Received: 24 February 2013 Accepted: 19 June 2013

Published: 24 June 2013

\section{References}

1. Holtzer CA, Marani E, Lakke EA, Thomeer RT: Repair of ventral root avulsions of the brachial plexus: a review. J Peripher Nerv Syst 2002, 7:233-242.

2. Bertelli JA, Ghizoni MF: Concepts of nerve regeneration and repair applied to brachial plexus reconstruction. Microsurgery 2006, 26:230-244.

3. Risling M, Fried K, Linda H, Carlstedt T, Cullheim S: Regrowth of motor axons following spinal cord lesions. Distribution of laminin and collagen in the CNS scar tissue. Brain Res Bull 1993, 30:403-413.

4. Remahl S, Angeria M, Remahl IN, Carlstedt T, Risling M: Observations at the CNS-PNS Border of Ventral Roots Connected to a Neuroma. Front Neurol 2010, 25:136.

5. Bertelli JA, Mira JC: Brachial plexus repair by peripheral nerve grafts directly into the spinal cord in rats. Behavioral and anatomical evidence of functional recovery. J Neurosurg 1994, 81:107-114. 
6. Wu W, Han K, Li L, Schinco FP: Implantation of PNS graft inhibits the induction of nitric oxide synthase and enhances the survival of spinal motoneurons due to root avulsion. Exp Neurol 1994, 129:335-339.

7. Moissonnier P, Reviron T, Ye JH, Horvat JC: Motoneurons of the injured spinal cord of the adult dog can grow lengthy axons into an autologous peripheral nerve graft. A retrograde axonal tracing study. Spinal Cord 1996, 34:320-325.

8. Novikova L, Novikov L, Kellerth JO: Effects of neurotransplants and BDNF on the survival and regeneration of injured adult spinal motoneurons. Eur J Neurosci 1997, 9:774-2777.

9. Rhrich-Haddout F, Kassar-Duchossoy L, Bauchet L, Destombes J, Thiesson D, Butler-Browne G, Lyoussi B, Baillet-Derbin C, Horvat JC: Alpha-motoneurons of the injured cervical spinal cord of the adult rat can reinnervate the biceps brachii muscle by regenerating axons through peripheral nerve bridges: combined ultrastructural and retrograde axonal tracing study. J Neurosci Res 2001, 64:476-486.

10. Holtzer CA, Marani E, van Dijk GJ, Thomeer RT: Repair of ventral root avulsion using autologous nerve grafts in cats. J Peripher Nerv Syst 2003, 8:17-22.

11. Su HX, Zhang WM, Guo JS, Guo AC, Yuan QJ, Wu W: Neural progenitor cells enhance the survival and axonal regeneration of injured motoneurons after transplantation into the avulsed ventral horn of adult rats. J Neurotrauma 2009, 26:67-80.

12. Bertelli JA, Ghizoni MF: Brachial plexus avulsion injury repairs with nerve transfers and nerve grafts directly implanted into the spinal cord yield partial recovery of shoulder and elbow movements. Neurosurgery 2003, 52:1385-1389.

13. Fournier HD, Menei $P$, Mercier $P$ : Ideal intraspinal implantation site for the repair of ventral root avulsion after brachial plexus injury in humans. $A$ preliminary anatomical study. Surg Radiol Anat 2001, 23:191-195.

14. Carlstedt T, Aldskogius H, Hallin RG, Nilsson-Remahl I: Novel surgical strategies to correct neural deficits following experimental spinal nerve root lesions. Brain Res Bull 1993, 30:447-451.

15. Hallin RG, Carlstedt T, Nilsson-Remahl I, Risling M: Spinal cord implantation of avulsed ventral roots in primates; correlation between restored motor function and morphology. Exp Brain Res 1999, 124:304-310.

16. Carlstedt T, Anand P, Hallin R, Misra PV, Nore" $n$ G, Seferlis T: Spinal nerve root repair and reimplantation of avulsed ventral roots into the spinal cord after brachial plexus injury. J Neurosurg Spine 2000, 93:237-247.

17. Blits B, Carlstedt TP, Ruitenberg MJ, de Winter F, Hermens WT, Dijkhuizen PA, Claasens JW, Eggers R, van der Sluis R, Tenenbaum L, Boer GJ, Verhaagen J: Rescue and sprouting of motoneurons following ventral root avulsion and reimplantation combined with intraspinal adeno-associated viral vectormediated expression of glial cell line-derived neurotrophic factor or brain-derived neurotrophic factor. Exp Neurol 2004, 189:303-316.

18. Eggers $\mathrm{R}$, Tannemaat MR, Ehlert EM, Verhaagen J: A spatio-temporal analysis of motoneuron survival, axonal regeneration and neurotrophic factor expression after lumbar ventral root avulsion and implantation. Exp Neurol 2010, 223:207-220.

19. Carlstedt T, Havton L: The longitudinal spinal cord injury: Lessons from intraspinal plexus, cauda equina and medullary conus lesions. Handb Clin Neurol 2012, 109:337-354.

20. Chai $H$, Wu W, So KF, Yip H: Survival and regeneration of motoneurons in adult rats by re-implantation of ventral root following spinal root avulsion. NeuroReport 2000, 11:1249-1252.

21. Gu HY, Chai H, Zhang JY, Yao ZB, Zhou LH, Wong WM, Bruce I, Wu W: Survival, regeneration and functional recovery of motoneurons in adult rats by reimplantation of ventral root following spinal root avulsion. Eur J Neurosci 2004, 19:2123-2131.

22. Gu HY, Chai H, Zhang JY, Yao ZB, Zhou LH, Wong WM, Bruce IC, Wu WT: Survival, regeneration and functional recovery of motoneurons after delayed reimplantation of avulsed spinal root in adult rat. Exp Neurol 2005, 192:89-99.

23. Li L, Wu W, Lin LF, Lei M, Oppenheim RW, Houenou LJ: Rescue of adult mouse motoneurons from injury-induced cell death by a glial cell line-derived neurotrophic factor. Proc Natl Acad Sci USA 1995, 92:9771-9775

24. Wu W: Potential roles of gene expression change in adult rat spinal motoneurons following axonal injury: a comparison among c-jun, off-affinity nerve growth factor receptor (LNGFR), and nitric oxide synthase (NOS). Exp Neurol 1996, 141:190-200.
25. Kline DG, Donner TR, Happel L, Smith B, Richter HP: Intraforaminal repair of plexus spinal nerves by a posterior approach: an experimental study. J Neurosurg 1992, 76:459-470.

26. Lang EM, Schlegel N, Sendtner M, Asan E: Effects of root replantation and neurotrophic factor treatment on long-term motoneuron survival and axonal regeneration after C7 spinal root avulsion. Exp Neurol 2005, 194:341-354.

27. Hoffmann CF, Thomeer RT, Marani E: Reimplantation of ventral rootlets into the cervical spinal cord after their avulsion: an anterior surgical approach. Clin Neurol Neurosurg 1993, 95:S112-S118.

28. Holtzer CA, Dahan A, Verschure PC, van Dijk JG, Marani E, Thomeer RT: Nerve grafting from spinal cord to spinal nerve: a microsurgical technique in cats. J Neurosci Methods 1996, 70:163-169.

29. Hoffmann CF, Thomeer RT, Marani E: Ventral root avulsions of the cat spinal cord at the brachial plexus level (cervical 7). Eur J Morphol 1990, 28:418-429.

30. Hoffmann CF, Marani E, Gert VD, Kamp W, Thomeer RT: Reinnervation and reimplanted ventral rootlets in the cervical spinal cord of the cat. J Neurosurg 1996, 8:234-243.

31. Fraher JP: The transitional zone and CNS regeneration. J Anat 1999, 194:161-182.

32. Höke A, Redett R, Hameed H, Jari R, Zhou C, Li ZB, Griffin JW, Brushart TM: Schwann cells express motor and sensory phenotypes that regulate axon regeneration. J Neurosci 2006, 26:9646-9655.

33. Ruigrok TJ, Crowe A, Donkelaar HJ: Dendrite distribution of identified motoneurons in the lumbar spinal cord of the turtle Pseudemys scripta elegans. J Comp Neurol 1985, 238:275-285.

34. Cullheim S, Wallquist W, Hammarberg H, Linda H, Piehl F, Carlstedt T, Risling $M$ : Properties of motoneuros underlying their regenerative capacity after axon lesions in the ventral funiculus or at the surface of the spinal cord. Brain Res. Brain Res Rev 2002, 40:309-316.

doi:10.1186/1471-2482-13-21

Cite this article as: Su et al.: Ventral root re-implantation is better than peripheral nerve transplantation for motoneuron survival and regeneration after spinal root avulsion injury. BMC Surgery 2013 13:21.

\section{Submit your next manuscript to BioMed Central and take full advantage of:}

- Convenient online submission

- Thorough peer review

- No space constraints or color figure charges

- Immediate publication on acceptance

- Inclusion in PubMed, CAS, Scopus and Google Scholar

- Research which is freely available for redistribution
C) Biomed Central 